\title{
Long-term stability of an infusion containing paracetamol, alizapride, ketorolac and tramadol in glass bottles at $5 \pm 3^{\circ} \mathrm{C}$
}

\author{
Marie-Lise Colsoul, ${ }^{1}$ Jean-Daniel Hecq, ${ }^{2}$ Laura Soumoy, ${ }^{2}$ Océane Charles, ${ }^{1}$ \\ Nicolas Goderniaux, ${ }^{1}$ Benoît Bihin, ${ }^{3}$ Jacques Jamart, ${ }^{3}$ Laurence Galanti ${ }^{1}$
}

'Medical Laboratory, CHU UCL Namur, Yvoir, Belgium 2Pharmacy, CHU UCL Namur, Yvoir, Belgium

${ }^{3}$ Scientific Support Unit, $\mathrm{CHU}$ UCL Namur, Yvoir, Belgium

Correspondence to Marie-Lise Colsoul, Laboratory, CHU UCL Namur, Yvoir 5530, Belgium; marie-lise.colsoul@ uclouvain.be

Received 8 April 2019 Revised 18 April 2019 Accepted 8 May 2019 Published Online First 11 June 2019

\section{EAHP Statement 3:} Production and Compounding.

\section{ABSTRACT}

Background and objective Infusion containing paracetamol, alizapride, ketorolac and tramadol is used after a general anaesthesia in order to limit pain, fever and nausea. Currently, these infusions are prepared according to demand in the anaesthesia unit, but the preparation in advance could improve quality of preparation and time management. The aim of this study was to investigate the long-term stability of this infusion in glass bottles at $5^{\circ} \mathrm{C} \pm 3^{\circ} \mathrm{C}$.

Method Five bottles of infusion were stored at $5^{\circ} \mathrm{C}$ $\pm 3{ }^{\circ} \mathrm{C}$ for 60 days. A visual and microscope inspection were performed periodically to observe any particle appearance or colour change. pH and absorbance at three wavelengths were measured. The concentrations were measured by ultra-high performance liquid chromatography - diode array detection.

Results Multiple verifications were performed during the first 35 days and no crystal, impurity or colour change were observed. At the next time point (42nd day), crystals were visible to the naked eye. $\mathrm{pH}$ and absorbance at $350 \mathrm{~nm}$ and $550 \mathrm{~nm}$ were stable. A slight increase in the absorbance at $410 \mathrm{~nm}$ was observed during the study, suggesting that a degradation product could be formed and absorb at this wavelength. The infusion was considered chemically stable while the lower one-sided prediction limit at 95\% remains superior to $90 \%$ of the initial concentration. Concentration measurements demonstrated that ketorolac and alizapride remained stable in the infusion for 35 days. The stability of tramadol was 28 days. However, degradation of paracetamol was much faster given that concentration has fallen below $90 \%$ of the initial concentration after 7 days.

Conclusion Infusion of paracetamol, alizapride, ketorolac and tramadol remains stable for 7 days in glass bottles at $5^{\circ} \mathrm{C} \pm 3^{\circ} \mathrm{C}$ and could be prepared in advance with these storage conditions.

\section{INTRODUCTION}

During the post-operative period, multimodal analgesia is recommended to manage patient pain efficiently. The multimodal strategy consists in injecting several drugs with different analgesic mechanisms to benefit from the synergy of their actions and minimise side effects by using optimal dosages for each agent. ${ }^{1-5}$ In order to limit the number of injections, it is common for anaesthesia staff to mix all the components of infusion and inject patients only once. Therefore, patients are perfused with a combination of paracetamol, alizapride, ketorolac and tramadol to limit pain, fever, nausea and vomiting after a general anaesthesia.

Paracetamol is an analgesic and antipyretic drug widely used because of its good tolerance and its weak adverse effects. ${ }^{67}$ Tramadol acts as a weak opioid agonist and relieves mild to severe postoperative pain. However, it can cause adverse events, such as nausea and vomiting. ${ }^{3}{ }^{8}$ Ketorolac is also an analgesic and is a part of the nonsteroidal anti-inflammatory drugs (NSAIDs) family. It is used in combination with opioid to achieve an adequate analgesia while limiting side effects. ${ }^{9}$ In addition to pain, nausea and vomiting are common inconveniences after surgery under general anaesthesia. ${ }^{10}$ Post-operative nausea and vomiting can be prevented by alizapride, an antiemetic agent. ${ }^{10} 11$

Currently, infusions containing the four active principles are reconstituted according to demand by the anaesthesia staff. However, these infusions could be prepared in advance by a Centralised Intravenous Additive Service (CIVAS) to improve time management and preparations quality. ${ }^{12} 13$ This purpose requires the awareness of the stability of each component in the infusion. Some data are available about the compatibility and stability of alizapride with tramadol, ${ }^{14}$ ketorolac with tramadol, ${ }^{15} 16$ paracetamol with tramadol ${ }^{17}$ and paracetamol with ketorolac. ${ }^{18}$ Nevertheless, longterm stability of the quaterny mixture remains unknown. At anaesthesia unit request, the stability of infusion containing paracetamol, alizapride, ketorolac and tramadol was assessed in glass bottle at $5^{\circ} \mathrm{C} \pm 3^{\circ} \mathrm{C}$ in order to evaluate the possibility of a centralised preparation. Consequently, the anaesthesia unit could be provided with ready-to-use injectables containing the four drugs.

\section{MATERIALS AND METHODS \\ Solutions preparation}

Five bottles of infusion were prepared under aseptic conditions by injection of alizapride (Litican 50 mg/2 mL, lot DY007, Sanofi, Diegem, Belgium), ketorolac (Taradyl $10 \mathrm{mg} / 1 \mathrm{~mL}$, lot F1015F01, Atnahs, London, United Kingdom) and tramadol (Contramal 100 mg/2 mL, lot 009231, Grünenthal, Nanterre, France) in glass bottles of paracetamol (1 g/100 mL, lot 14LI38, Fresenius Kabi, Schelle, Belgium). Final solutions contained approximately $476 \mu \mathrm{g} / \mathrm{mL}$ alizapride, $190 \mu \mathrm{g} / \mathrm{mL}$ ketorolac, 952 $\mu \mathrm{g} / \mathrm{mL}$ tramadol and $9524 \mu \mathrm{g} / \mathrm{mL}$ paracetamol.

Solutions were stored at $5^{\circ} \mathrm{C} \pm 3^{\circ} \mathrm{C}$ during the study and aliquots were taken with following 

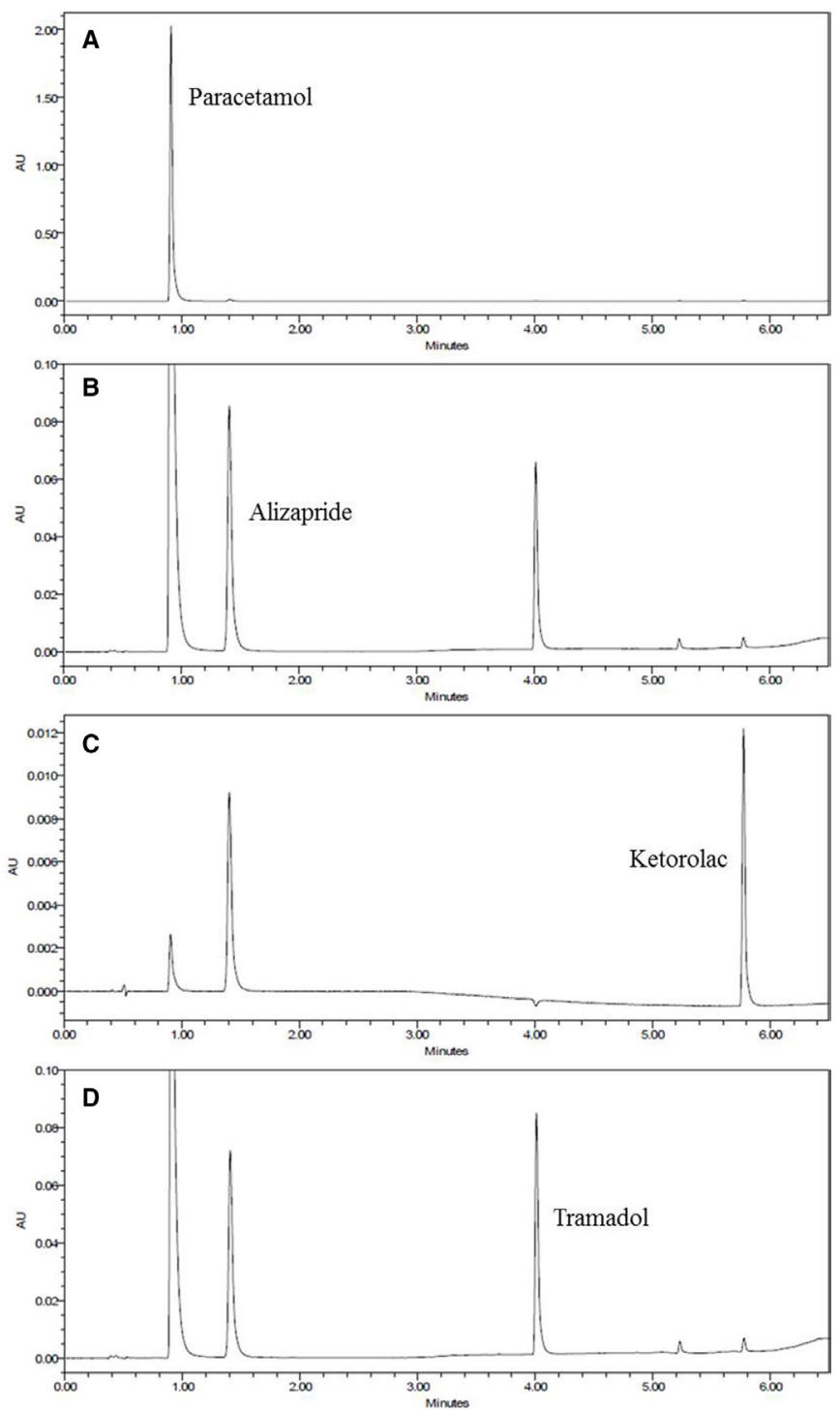

Figure 1 Chromatograms obtained for injection of $5 \mu$ of 1:100 diluted infusion (initially containing $9524 \mu \mathrm{g} / \mathrm{mL}$ paracetamol, $476 \mu \mathrm{g} / \mathrm{mL}$ alizapride, $190 \mu \mathrm{g} / \mathrm{mL}$ ketorolac and $952 \mu \mathrm{g} / \mathrm{mL}$ tramadol) at $243 \mathrm{~nm}(\mathrm{~A})$, $223 \mathrm{~nm}(\mathrm{~B}), 312 \mathrm{~nm}$ (C) and $215 \mathrm{~nm}$ (D).

frequency: first week every day, three times per week during the second to fourth weeks' period and finally once a week during the second month. One aliquot was immediately analysed in order to assess the solutions physical stability while another one was frozen at $-80^{\circ} \mathrm{C}$. All samples were defrosted at room temperature at the end of the study for chemical stability evaluation.

\section{Physical stability}

Each time point of analysis, solutions were visually inspected in front of black and white backgrounds in order to observe any particle appearance or colour change. Crystals were searched under a microscope 80X (Jenamed, Carl Zeiss, Germany) after the solutions centrifugation at $2150 \mathrm{~g}$ for $5 \mathrm{~min}$ (Heraeus multifuge 1S, Thermo Scientific, USA). The stability of $\mathrm{pH}$ was assessed thanks to measurements with a glass electrode $\mathrm{pH}$ meter (InoLab, WTW GmbH, Germany). Optical densities at three wavelengths $(350,410$ and $550 \mathrm{~nm})$ were measured with a spectrophotometer (Genesys $10 \mathrm{UV}$, Spectronic Unican, USA) to test turbidity and detect subvisible particles. ${ }^{19}$
Table 1 Calibrators and controls concentrations

\begin{tabular}{llcccc}
\hline & & $\begin{array}{l}\text { Paracetamol } \\
(\mu \mathrm{g} / \mathrm{ml})\end{array}$ & $\begin{array}{l}\text { Alizapride } \\
(\mu \mathrm{g} / \mathrm{ml})\end{array}$ & $\begin{array}{l}\text { Ketorolac } \\
(\mu \mathrm{g} / \mathrm{ml})\end{array}$ & $\begin{array}{l}\text { Tramadol } \\
(\mu \mathrm{g} / \mathrm{ml})\end{array}$ \\
\hline Calibrator 1 & - & 1905 & 95 & 38 & 190 \\
Calibrator 2 & Control 1 & 3810 & 190 & 76 & 381 \\
Calibrator 3 & - & 5714 & 286 & 114 & 571 \\
Calibrator 4 & Control 2 & 9524 & 476 & 190 & 952 \\
Calibrator 5 & Control 3 & 11429 & 571 & 229 & 1143 \\
\hline
\end{tabular}

\section{Chemical stability}

Chromatographic conditions

Molecules concentrations were measured by chromatography. Analyses were performed with an ultra-high performance liquid chromatography (UHPLC) system coupled with photodiode array (PDA) detection (Acquity, Waters, Milford, USA) and Empower 3 as processing software (Waters). A reverse phase column (Acquity UPLC BEH C18 $130 \AA 1.7 \mu \mathrm{m} 2.1 \mathrm{~mm} \mathrm{X} 100$ $\mathrm{mm}$, lot 0311380032, Waters) with a pre-column (Acquity UPLC BEH C18 VanGuard Pre-column $130 \AA 1.7 \mu \mathrm{m} 2.1 \mathrm{~mm}$ X 5 mm, lot 0307372572 , Waters) was used at $30^{\circ} \mathrm{C}$ with a flow rate of $0.6 \mathrm{~mL} / \mathrm{min}$. A gradient separation was carried out with water pH 2 (adjusted with phosphoric acid 85 wt. \% in water, SigmaAldrich, lot MKCB7708, Saint-Louis, USA) and acetonitrile (Biosolve, lot 1215101, Dieuze, France). The run started with a low organic content (10\%) for 2 min before being gradually increased to $45 \%$ in $4 \mathrm{~min}$. Conditions were kept during $1 \mathrm{~min}$ and the column was then reequilibrated for $3 \mathrm{~min} .5 \mu \mathrm{l}$ of $1: 100$ diluted samples in water (B. Braun, lot 180218091, Melsungen, Germany) were injected. Chromatograms were extracted from wavelengths scan at absorption maximum for each molecule: $243 \mathrm{~nm}$ (paracetamol), $223 \mathrm{~nm}$ (alizapride), $312 \mathrm{~nm}$ (ketorolac) and $215 \mathrm{~nm}$ (tramadol).

UHPLC was also coupled with a QDa detector (Acquity, Waters) for full scan mass analyses. The same conditions were used except the aqueous phase for the elution gradient which was $0.1 \%$ formic acid (Biosolve, lot 1198871, Dieuze, France) in water.

\section{Standard and control solutions}

Standard and control solutions were prepared each working day by dilution of a fresh mixture of paracetamol, alizapride, ketorolac and tramadol in purified water in the same proportion as the studied infusion. A calibration curve was carried out based on five levels of calibrator and a weighted regression procedure $(1 / \mathrm{X})$ was performed. Three levels of control were used (table 1). Solutions were diluted 1:100 in water before UHPLC injection.

\section{Validation of the UHPLC method}

Following the ICH Q2 (R1) guidelines, the chromatographic method was validated based on linearity, precision, detection and quantification limits. A forced degradation study was also carried out to assess the stability-indicating capability of the method. $^{20}$

\section{Linearity}

The range of linearity was determined once by two-fold serial dilutions (14 dilutions were performed) from a fresh mixture containing $13334 \mu \mathrm{g} / \mathrm{mL}$ paracetamol, $668 \mu \mathrm{g} / \mathrm{mL}$ alizapride, $267 \mu \mathrm{g} / \mathrm{mL}$ ketorolac and $1333 \mu \mathrm{g} / \mathrm{mL}$ tramadol. A highly concentrated mixture was used in order to verify that injectables 
could be quantified in the linearity range. All solutions were diluted 1:100 in water before injection.

\section{Precision}

Precision was considered at two levels: repeatability (intra-day) and intermediate precision (inter-day). Both levels were evaluated by 10 measurements for three concentrations, corresponding to controls used every working day.

\section{Detection and quantification limits}

Limits of detection (LOD) and quantification (LOQ) were calculated based on mean and SD obtained for water injections $(n=10)$. LOD was estimated as mean plus three times the SD and LOQ as mean plus 10 times the SD.

\section{Stability indication}

Six conditions were tested for forced degradation of solutions containing only one active principle (paracetamol, alizapride, ketorolac or tramadol): natural, acidic $(\mathrm{HCl})$ and basic $(\mathrm{NaOH})$ conditions before and after heating at $100^{\circ} \mathrm{C}$ for 1 hour. Samples were injected in UHPLC and interfering peaks were searched in each chromatogram extracted at the specific wavelength of the studied molecule.

\section{Chemical stability study}

Aliquots of a same bottle of infusion were defrosted at room temperature for UHPLC analysis the same day. This allowed a reduction in results variability within a same bottle due to experiment conditions. Samples were diluted 1:100 in triplicate in purified water before injection.

\section{Statistical analysis}

As defined in the ICH Q1E, the shelf life of the product was defined as "the earliest time at which the 95 per cent confidence limit for the mean intersects the proposed acceptance criterion". ${ }^{21}$ Therefore, a unilateral $95 \% \mathrm{CI}$ on the mean was used to determine the earliest time at which the product concentration fall under $90 \%$ of the initial concentration or $95 \%$ of the initial concentration when any signs of physical instability exist. ${ }^{22}$

However, as stated by the Shelf-Life Working Group of the Product Quality Research Institute, the definition of the shelf life should be based on "an acceptably small proportion of product exceeding an acceptance criterion". ${ }^{23}$ We thus confirmed our analyses with the use of $95 \%$ unilateral prediction interval in lieu of the CI. A 95\% prediction interval is an interval that covers, on average, $95 \%$ of the distribution.

\section{RESULTS AND DISCUSSION Physical stability}

No crystal, impurity or colour change were observed during the first 35 days of storage at $5^{\circ} \mathrm{C} \pm 3^{\circ} \mathrm{C}$. At the next time point $(42$ nd day), crystals were visible to the naked eye in all bottles. The physical stability study was, therefore, stopped after 42 days. In order to assess the temperature effect, bottles were kept at room temperature and dissolution of crystals was visible after 3 days. $\mathrm{pH}($ mean \pm SD: $5.88 \pm 0.06)$ and absorbance at 350 $\mathrm{nm}(2.377 \pm 0.095)$ and $550 \mathrm{~nm}(0.000 \pm 0.001)$ were stable during the study, including while crystals appeared. Despite a low absorption at $410 \mathrm{~nm}$, a slight increase in the absorbance at this wavelength $(0.004 \pm 0.003)$ was observed during the 42 days, suggesting that a degradation product could be formed and absorb at this wavelength.
Table 2 Linearity, detection and quantification limits for each molecule

\begin{tabular}{lllllll}
\hline & \multicolumn{2}{l}{ Linearity } & & & Limit of \\
& \cline { 2 - 6 } & $\begin{array}{l}\text { Range }(\mu \mathrm{g} / \\
\mathrm{ml})\end{array}$ & Equation & $\mathrm{R}^{\mathbf{2}}$ & $\begin{array}{l}\text { Limit of } \\
(\mu \mathrm{g} / \mathrm{ml})\end{array}$ & $\begin{array}{l}\text { quantification } \\
(\mu \mathrm{g} / \mathrm{ml})\end{array}$ \\
\hline Paracetamol & $1-13330$ & $1.0297 \mathrm{x}$ & 1 & $<0.001$ & $<0.001$ \\
\hline Alizapride & $0.7-668$ & $0.9493 \mathrm{x}$ & 0.9999 & 0.090 & 0.188 \\
\hline Ketorolac & $8.3-266$ & $1.0522 \mathrm{x}$ & 0.9871 & 0.272 & 0.678 \\
\hline Tramadol & $1.3-1333$ & $0.9538 \mathrm{x}$ & 0.9999 & 0.319 & 0.802 \\
\hline
\end{tabular}

\section{UHPLC method development}

Molecules chemical structures were examined before starting the method development. The logarithm of the partition coefficient $(\log \mathrm{P})$ for each component indicated that molecules were hydrophobic (paracetamol: 0.91, alizapride: 1.13, ketorolac: 2.28, tramadol: 2.45), suggesting the use of a C18 column. $\mathrm{pH}$-distributions of species were analysed to determine $\mathrm{pH}$ of the mobile phase. It was set at $\mathrm{pH} 2$, given that a unique species for each molecule was in solution at this $\mathrm{pH}$, avoiding separation variability due to $\mathrm{pH}$ variations. Water adjusted to $\mathrm{pH} 2$ with phosphoric acid $\left(\mathrm{pK}_{1} 2.12\right)$ was chosen because phosphate could act as a buffer at $\mathrm{pH}$ of interest. A gradient elution with acetonitrile was performed to optimise separation of early eluted peaks and accelerate late elutions. The four wavelengths of analysis were chosen thanks to molecules spectra obtained with the PDA scan: wavelengths corresponding to absorption maxima were selected. Anyway, all molecules were visible on each chromatogram extracted at the chosen wavelengths, but at different intensities. Several injection volumes and sample dilutions were investigated and were fixed at $5 \mu \mathrm{l}$ of 1:100 diluted sample in order to obtain reproducible signals without any detector saturation. Three flow rates were tested $(0.4-0.5-0.6 \mathrm{~mL} / \mathrm{min})$ before choosing $0.6 \mathrm{~mL} / \mathrm{min}$, allowing a fast analysis and a decrease of peaks tailing. The final method allowed quantification of each molecule of interest in the studied mixture with just one UHPLC injection (figure 1).

\section{UHPLC method validation}

Linearity, detection and quantification limits of the method (table 2) allowed correct molecules quantification in the studied injectable solution. Precision for intra- and inter-assay for quantification of each molecule was evaluated by the relative standard deviation which was lower than $2.20 \%$ (table 3). A forced degradation test showed diminution of all peaks of interest and the appearance of some small peaks corresponding to degradation products (figure 2), especially for tramadol at acidic $\mathrm{pH}$ after heating (figure 2D). However, no interference with peaks of interest was detected. The UHPLC method was, therefore, stability-indicating for the four components.

\section{Chemical stability}

Alizapride and ketorolac were stable in the infusion during the 35 first days of analysis (figure 3B,C) given that during this period the lower limit of the one-sided $95 \%$ prediction interval remained superior to $90 \%$ of the initial concentration for these molecules. Tramadol was stable for 28 days (figure 3D). However, paracetamol was stable for only 7 days (figure 3A) but no degradation product was observed on chromatograms. Given that paracetamol showed chemical instability, solutions were additionally analysed with a mass detector looking for known degradation products of paracetamol: 4-aminophenol, the main degradation product which can be formed by hydrolysis during the storage of paracetamol 
Table 3 Precision for intra- and inter-assay for each molecule $(n=10)$

\begin{tabular}{|c|c|c|c|c|c|c|}
\hline $\begin{array}{l}\text { Concentration mean } \pm \mathrm{SD} \mu \mathrm{g} / \\
\mathrm{mL}(\mathrm{RSD} \%)\end{array}$ & Intra-day & & & Inter-day & & \\
\hline Paracetamol & $3890 \pm 0(0.23)$ & $9672 \pm 0(0.16)$ & $11729 \pm 0(0.08)$ & $3868 \pm 41(1.05)$ & $9634 \pm 38(0.39)$ & $11396 \pm 163(1.43)$ \\
\hline Alizapride & $189 \pm 1(0.33)$ & $478 \pm 1(0.21)$ & $588 \pm 1(0.15)$ & $192 \pm 3(1.68)$ & $478 \pm 4(0.84)$ & $569 \pm 10(1.70)$ \\
\hline Ketorolac & $77 \pm 1(1.16)$ & $192 \pm 1(0.43)$ & $237 \pm 1(0.49)$ & $77 \pm 2(2.20)$ & $191 \pm 3(1.31)$ & $230 \pm 4(1.73)$ \\
\hline Tramadol & $382 \pm 0(0.11)$ & $964 \pm 1(0.12)$ & $1180 \pm 1(0.12)$ & $381 \pm 4(1.00)$ & $958 \pm 9(0.95)$ & $1146 \pm 18(1.53)$ \\
\hline
\end{tabular}

preparation, 1,4-benzoquinone, 4-nitrophenol, hydroquinone and $\mathrm{N}$-acetyl-p-benzoquinone imine. ${ }^{24-28}$ None of them could be distinguished from the background noise. The physicochemical results allow us to add this solution to the list of our systematic studies of the long-term stability of ready-to-use intravenous drug solutions ${ }^{29}$ and the advance preparation by a CIVAS may be considered. ${ }^{12} 13$ Physicochemical stability was only evaluated and the microbiological aspects were not investigated. However, according to Chapter 797 of the United States Pharmacopoeia, this preparation can be assimilated to low-risk compounding. ${ }^{30}$

\section{CONCLUSION}

The stability of infusion containing paracetamol, alizapride, ketorolac and tramadol in glass bottles at $5^{\circ} \mathrm{C} \pm 3^{\circ} \mathrm{C}$ was evaluated in order to prepare it in advance and provide the anaesthesia unit with ready-to-use injectables. Actually, patients are injected with this infusion after a general anaesthesia to limit pain, fever, nausea and vomiting. This study showed that the infusion was physically stable for 35 days before precipitating. However, it was chemically stable for only 7 days due to a rapid
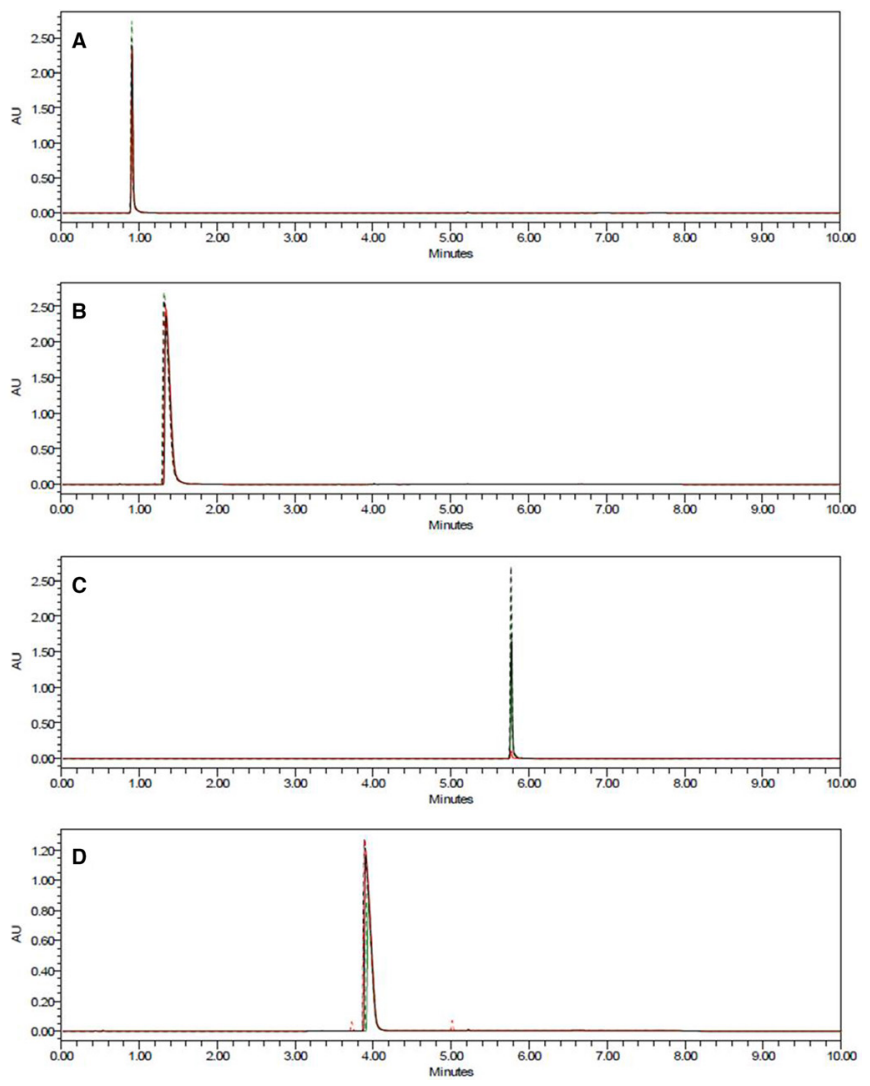

Figure 2 Forced degradation chromatograms of paracetamol (A), alizapride (B), ketorolac (C) and tramadol (D). Before heating: - natural, acidic, - basic pH. After heating: -- natural, -- acidic, -- basic $\mathrm{pH}$. decrease of paracetamol concentration. The infusion could be prepared in advance by a centralised unit and be stored for 7 days maximum at $5^{\circ} \mathrm{C} \pm 3^{\circ} \mathrm{C}$.

\section{What this paper adds}

What is already known on this subject

- Compatibility and stability of some components of the infusion were known: alone or with one another

- Long-term stability of the four components (paracetamol, alizapride, ketorolac and tramadol) together in glass bottles at $5^{\circ} \mathrm{C} \pm 3^{\circ} \mathrm{C}$ remained unknown

What this study adds

- The infusion is physically stable for 35 days before precipitating

- The four active principles are chemically stable in the infusion during 7 days

- The infusion preparation in advance by a centralised unit could be considered

Contributors M-LC, J-D H, LS, OC, NG and LG designed the study; M-LC and OC performed experiments; M-LC, OC and BB analysed data; M-LC and LG wrote the paper.

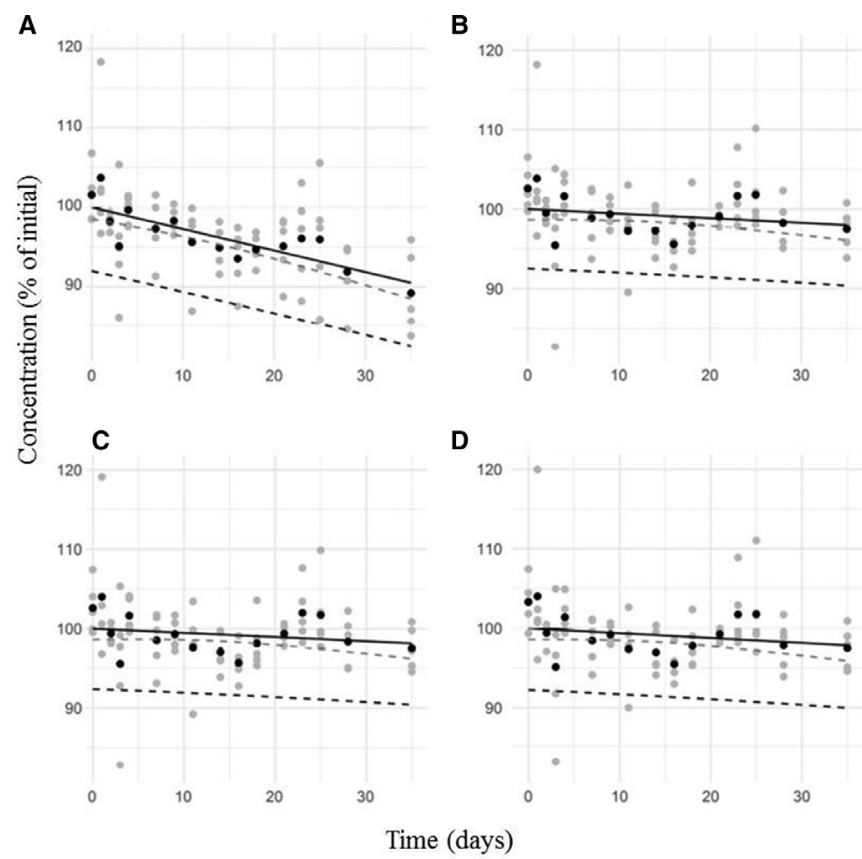

Figure 3 Relative concentration evolution vs time for paracetamol (A), alizapride (B), ketorolac (C) and tramadol (D) contained in infusion bottles at $5^{\circ} \mathrm{C} \pm 3^{\circ} \mathrm{C}$. Grey dots: observations for each studied bottle, black dots: observations means, black line: mean estimated by the linear regression, grey dotted line: lower limit of the one-sided $95 \% \mathrm{Cl}$, black dotted line: lower limit of the one-sided 95\% prediction interval. 
Funding The authors have not declared a specific grant for this research from any funding agency in the public, commercial or not-for-profit sectors.

Competing interests None declared.

Patient consent for publication Not required.

Provenance and peer review Not commissioned; internally peer reviewed.

Data availability statement All data relevant to the study are included in the article or uploaded as supplementary information.

\section{REFERENCES}

1 Kehlet $\mathrm{H}$, Dahl JB. Anaesthesia, surgery, and challenges in postoperative recovery. Lancet 2003:362:1921-8.

2 Mandel JE. Considerations for the use of short-acting opioids in general anesthesia. J Clin Anesth 2014;26(1 Suppl):S1-S7.

3 Stevens AJ, Woodman RJ, Owen H. The effect of ondansetron on the efficacy of postoperative tramadol: a systematic review and meta-analysis of a drug interaction. Anaesthesia 2015;70:209-18.

4 Asokumar B. Multimodal analgesia for perioperative pain management. International Anesthesia Research Society (IARS), 2011.

5 Hanna MN, Ouanes J-PP, Tomas VG. 18 - Postoperative Pain and Other Acute Pain Syndromes. In: Benzon HT, Rathmell JP, CLW, et al, eds. Practical management of pain. 5th edn. Philadelphia: Mosby, 2014: 271-9710.1016/B978-0-323-08340-9.00018-9.

6 Graham GG, Davies MJ, Day RO, et al. The modern pharmacology of paracetamol: therapeutic actions, mechanism of action, metabolism, toxicity and recent pharmacological findings. Inflammopharmacology 2013;21:201-32.

7 Hyllested M, Jones S, Pedersen JL, et al. Comparative effect of paracetamol, NSAIDs or their combination in postoperative pain management: a qualitative review. $\mathrm{Br} J$ Anaesth 2002:88:199-214.

8 Scott LJ, Perry CM. Tramadol: a review of its use in perioperative pain. Drugs 2000;60:139-76.

9 Vadivelu N, Gowda AM, Urman RD, et al. Ketorolac tromethamine - routes and clinical implications. Pain Pract 2015;15:175-93.

10 Rüsch D, Eberhart LHJ, Wallenborn J, et al. Nausea and vomiting after surgery under general anesthesia. Dtsch Arztebl Int 2010;107:733-41.

11 Bleiberg H, Gerard B, Dalesio O, et al. Activity of a new antiemetic agent: alizapride: a randomized double-blind crossover controlled trial. Cancer Chemother Pharmacol 1988:22:316-20.

12 Hecq J-D. Centralized intravenous additive services (CIVAS): the state of the art in 2010. Ann Pharm Fr 2011:69:30-7.

13 Hecq J-D. Ten years of European hospital pharmacy history: centralized intravenous additives services. EJHP 2004:10:47.
14 Athanasopoulos A, Hecq J-D, Vanbeckbergen D, et al. Long-term stability of the hydrochlorides of tramadol and alizapride in dextrose $5 \%$ polyolefin bag at $5 \pm 3^{\circ} \mathrm{C}$. Ann Pharm Fr 2010;68:157-62.

15 Cabrera J, Mancuso M, Cabrera-Fránquiz F, et al. Stability and compatibility of the mixture of tramadol, ketorolac, metoclopramide and ranitidine in a solution for intravenous perfusion. Farm Hosp 2018;15:80-3.

16 Lin T-F, Lin F-S, Chou W-H, et al. Compatibility and stability of binary mixtures of ketorolac tromethamine and tramadol hydrochloride injection concentrate and diluted infusion solution. Acta Anaesthesiol Taiwan 2010;48:117-21.

17 Balayssac D, Badaroux L, Rodier C, et al. Compatibility and stability of parenteral analgesic admixtures for multimodal analgesia. EJHP Science 2009;15:78-82.

18 Anderson C, Boehme S, Ouellette J, et al. Physical and chemical compatibility of injectable acetaminophen during simulated Y-Site administration. Hosp Pharm 2014;49:42-7

19 Lahlou A, Blanchet B, Carvalho M, et al. Mechanically-induced aggregation of the monoclonal antibody cetuximab. Ann Pharm Fr 2009;67:340-52.

20 ICH. Validation of Analytical Procedures: Text and Methodology Q2(R1). International conference on harmonisation of technical requirements for registration of pharmaceuticals for human use, 2005

21 International Conference on Harmonization (ICH). Guidance for industry Q1E evaluation of stability data, 2004

22 Bardin C, Astier A, Vulto A, et al. Guidelines for the practical stability studies of anticancer drugs: a European consensus Conference. Ann Pharm Fr 2011;69:221-31.

23 Capen $\mathrm{R}$, Christopher $\mathrm{D}$, Forenzo $\mathrm{P}$, et al. On the shelf life of pharmaceutical products. AAPS PharmSciTech 2012;13:911-8.

24 Sornchaithawatwong C, Vorrarat S, Nunthanavanit P. Simultaneous determination of paracetamol and its main degradation product in generic paracetamol tablets using reverse-phase HPLC.J Health Res 2010;24:103-6.

25 Villota N, Lomas JM, Camarero LM. Study of the paracetamol degradation pathway that generates color and turbidity in oxidized wastewaters by photo-Fenton technology. J Photochem Photobiol A Chem 2016;329:113-9.

26 Németh T, Jankovics P, Németh-Palotás J, et al. Determination of paracetamol and its main impurity 4-aminophenol in analgesic preparations by micellar electrokinetic chromatography. J Pharm Biomed Anal 2008;47:746-9.

27 MÁ LZ, Espinoza Estrada E. Degradation of acetaminophen and its transformation products in aqueous solutions by using an electrochemical oxidation cell with stainless steel electrodes. Water 2016;8:383.

28 Bhimavarapu R, Chitra KP, Meda H, et al. Forced degradation study of paracetamol in tablet formulation using RP-HPLC. Bull Pharm Res 2011;1:13-17.

29 Hecq J-D, Godet M, Jamart J, et al. Etude systématique de la stabilité chimique long terme de solutions de médications injectables prêtes l'emploi produites par une Unité Centrale de Reconstitution d'Injectables. J Pharm Belg 2015;97:36-44.

30 Trissel L. The new national standard for sterile preparation. Hosp Pharm 2004:39:900-4. 